\title{
Transepithelial Electric Potential Difference in Newborns Undergoing Phototherapy
}

\author{
K. JAEHRIG, E. H. BALLKE, A. KOENIG, AND P. MEISEL \\ Department of Pediatrics, University of Greifswald Medical School, Greifswald, East Germany
}

\begin{abstract}
When hyperbilirubinemic newborn babies underwent phototherapy, a significant decrease of the transepithelial electric potential difference of duodenal mucosa was observed, while the content of nonconjugated bilirubin and photobilirubins in the duodenal juice increased. This may indicate that the mucosa barrier function is damaged by bilirubin, with resulting increased sodium and water secretion into the gut. This phenomenon seems to be one of the reasons for diarrhea which is frequently observed in newborns undergoing phototherapy. Further investigations are necessary to understand the mechanism of bilirubin toxicity of the gut in detail. (Pediatr Res 21: 283-284, 1987)
\end{abstract}

Abbreviation

tPD, transepithelial electric potential difference

Watery diarrhea is a common side effect of phototherapy in hyperbilirubinemic babies. In our studies comprising a 5-yr period, about $20 \%$ of all infants undergoing phototherapy with visible light (420-480 $\mathrm{nm}$ ) have shown loose green stools beginning within about $3 \mathrm{~h}$ after the beginning of light exposure (1). The symptoms are mild and stop when the illumination is over.

In 1977, Bakken (2) suggested a blockade of intestinal lactase activity by nonconjugated bilirubin or bile acids as the mechanism responsible for the diarrhea as well as decreased gut transit time which had been previously described by Rubaltelli and Largajolli (3) and Wu et al. (4). However, Ebbesen et al. in 1980 $(5,6)$ found neither a significant influence of lactose concentration in milk when diarrhea occurred nor evidence for lactose malabsorption in their patients. Similarly experiments by Dinari et al. (7) and Whitington (8) in illuminated Gunn rats showed no reduction in activities of lactase, sucrase, or $\gamma$-glutamyl transpeptidase after irradiation when compared to controls kept in darkness. Incubation of normal intestinal mucosa in serum with varying concentrations of bile from a light-treated rat similarly had no effect on intestinal enzymatic activity. Therefore, intestinal lactase deficiency seems to be of no importance for the occasional loose stools during phototherapy.

Since Whitington and coworkers $(9-11)$ reported increased small bowel secretions in hamsters induced by nonconjugated bilirubin, we tried to confirm these results in human newborns under phototherapy.

\section{MATERIALS AND METHODS}

Fifteen light-treated newborns with normal birth weight (3095 $\pm 427 \mathrm{~g})$ and uncomplicated hyperbilirubinemia (293 $\pm 53 \mu \mathrm{mol} /$

Received May 16, 1985; accepted October 27, 1986.

Correspondence K. Jaehrig, Department of Pediatrics, Medical School, University of Greifswald, DDR-2200 Greifswald, East Germany. liter) were included in our study. Informed consent was given by parents of our patients as well as controls. The study was approved by the Ethical Committee of the Faculty of Medicine, EMA University of Greifswald. All infants received intense phototherapy on the 3rd or 4th day of life using a fairly monochromatic high pressure vapor lamp 400-04 NC (VEB Narva, Berlin) which produces a specific blue light intensity of $0.7 \mathrm{MW} / \mathrm{cm}^{2}$ at the matress (1). To characterize the gut function we estimated the tPD of the duodenal mucosa as described elsewhere (12-14). A duodenal tube filled and perfused with $1 \mathrm{M}$ potassium chloride solution $(0.2 \mathrm{ml} / \mathrm{h})$ was placed as a local surface electrode; a similar electrode was placed intravenously as a reference.

We estimated the baseline tPD of the gastric mucosa to calibrate the equipment. The immediate drop of tPD (from about 45 to $6 \mathrm{mV}$ ) after passing through the pylorus indicated that the catheter had reached the duodenum. We then inserted the catheter another $2 \mathrm{~cm}$ to locate it beyond the papilla of Vater. After that the tPD of the duodenal surface was recorded for about 15 min. Duodenal aspirate was collected for measurements of total bilirubin concentration (15) and of photobilirubin, particularly lumirubin (16).

The infant, lying on its back, was then exposed to light for 60 min. The tPD was recorded every $30 \mathrm{~s}$ during a $4-\mathrm{h}$ period. Bilirubin and photobilirubin content of the duodenal juice was estimated before and $30,60,120,180$ min after installing illumination. No fluid was administered orally during the examination. Estimations of bile acid concentrations were not performed in this study.

The control group comprised five 3-day-old mature newborns (birth weight $3200 \pm 220 \mathrm{~g}$ ) with serum bilirubin concentration of $210 \pm 102 \mu \mathrm{mol} /$ liter without phototherapy who were admitted for observation due to hyperbilirubinemia.

\section{RESULTS}

The baseline potential difference of gastric mucosa in our newborns was $44.9 \pm 4.5 \mathrm{mV}$ (as far as we know no data of newborns have thus far been reported). This value is completely within the range we found in healthy older infants and children (14).

In the duodenum a stable tPD of $6.1 \pm 2.4$ was measured. This value is slightly less than that found in infants older than 3 months, and is significantly lower compared with reference values measured in adults (17).

The change in tPD after starting phototherapy, and in relation to bile pigment content of duodenal juice, is demonstrated in Figure 1. The prompt decrease in tPD from $6.4 \pm 2.2$ to $3.6 \pm$ $2.2 \mathrm{mV}$ (mean $\pm \mathrm{SD}$ ) $15 \mathrm{~min}$ after light exposure is statistically significant ( $t$ test, $p<0.001$ ). During illumination and for the 3 $\mathrm{h}$ after therapy was terminated, the tPDs remained relatively constant at a low level. The tPD seemed to be closely related to the persistently increased bilirubin excretion into the bile (linear regression analysis, $r=-0.84$ ). The maximal concentrations of bilirubin and photobilirubin was reached after about $60 \mathrm{~min}$ of 


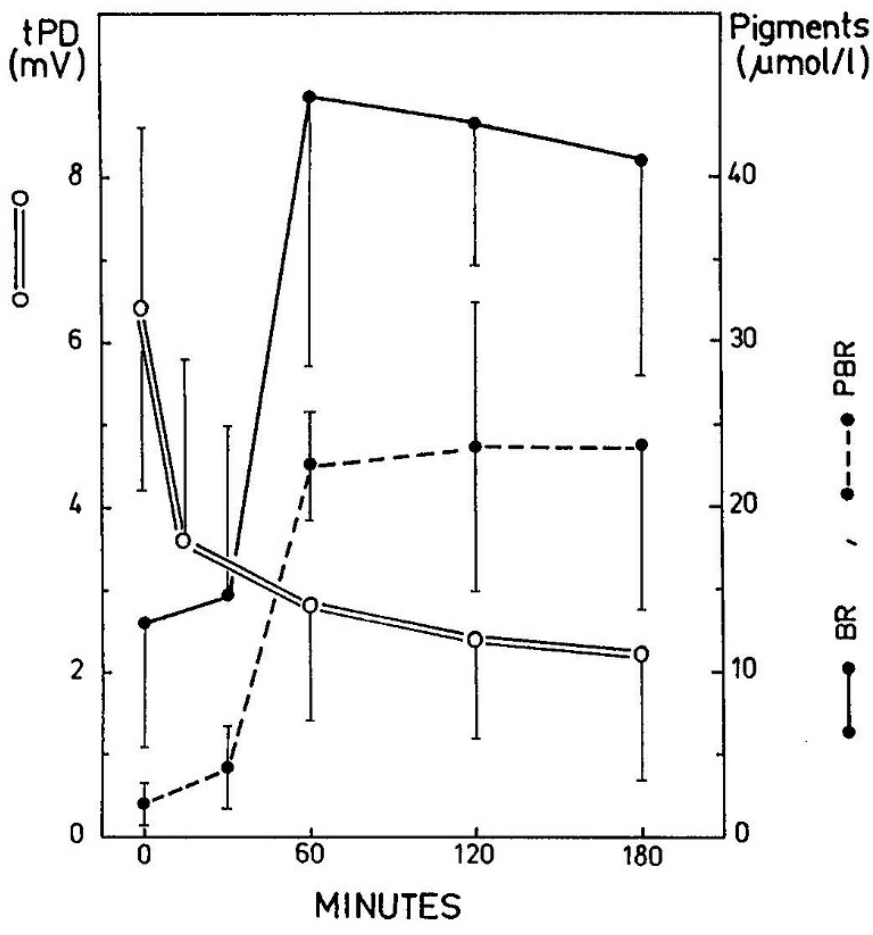

Fig. 1. Transepithelial potential difference (left abscissa) of duodenal mucosa during phototherapy ( $n=15$ newborn infants) and concentrations of bile pigments (right abscissa), bilirubin $\longrightarrow$ and photobilirubin $\bullet--\bullet$, resp., mean values \pm SD.

therapy, $8.9 \pm 3.2$ and $4.5 \pm 0.7 \mu \mathrm{mol} /$ liter (mean $\pm \mathrm{SD}$ ), respectively. The bilirubins measured in duodenal juice are $(\mathrm{Z}, \mathrm{Z})$ bilirubin, presumably the reversion product of the isomeric $(\mathrm{Z}, \mathrm{E})$ and (E,Z)-bilirubins, and (E,Z)-cyclo-bilirubin referred to here as "photobilirubin." The most common way to remove bilirubin from the body by light is the excretion of $(\mathrm{Z}, \mathrm{E})$-bilirubin and (E,Z)-cyclo-bilirubin (18).

No correlation was found between the serum bilirubin concentration, the baseline tPD of the duodenum, or the rate of tPD decrease during the trial. The gastric tPD showed a slight (negative) correlation with the serum bilirubin concentration (linear regression analysis, $p<0.05$ ). In five control infants without phototherapy, no significant changes in tPD could be detected during $3 \mathrm{~h}$ of investigation.

\section{DISCUSSION}

The significant decrease of tPD of the duodenal mucosa during phototherapy probably reflects a lesion of local barrier function. Previously we have observed similar reactions in different regions of intestinal mucosa in children and adults (14). For instance, the local administration of $\mathrm{N}$-acetyl cysteine, acetylsalicylic acid, or of bilirubin (albumin solution, bilirubin $170 \mu \mathrm{mol} / \mathrm{liter}$ ) led to a prompt and significant decrease in TPD of the rectum and the colonic mucosa. In patients with secretory diarrhea due to infections with enterotoxic Escherichia coli, we were able to detect a similar decrease in tPD in the lower intestinal tract during the acute phase of diseases, recovering to normal with resolution of the diarrhea.
These observations support our suggestion that increased hepatic excretion of unconjugated bilirubin induced by phototherapy leads to transient (functional) barrier damage particularly to the mucosa of the upper intestinal tract. An increased sodium excretion (and an enhanced net water flux into the lumen) is always associated with a decrease in $\operatorname{tPD}(13,14)$. Our results therefore support the data of Whitington and coworkers (9-11) and DeCurtis et al. (19) showing an association between increased excretion of sodium and water into the intestinal lumen and the diarrhea in phototreated hyperbilirubinemic newborns.

The exact mechanism by which bilirubin induces secretion has not as yet been clarified. The disruption of energy metabolism assumed to be a cause of brain damage in kernicterus (20) may be one also of the important factors here. Increased concentrations of bile salts in the colonic contents of light-treated jaundiced neonates (21) may also contribute to the diarrhea.

\section{REFERENCES}

1. Jaehrig K, Jaehrig D, Meisel P 1981 Phototherapie. VEB G Thieme, Leipzig, p 126

2. Bakken AF 1977 Temporary intestinal lactase deficiency in light-treated jaundiced infants. Acta Paediatr Scand 66:92-96

3. Rubaltelli FF, Largajolli G 1973 Effect of light exposure on gut transit time in jaundiced newborns. Acta Paediatr Scand 62:146-148

4. Wu PYK, Lim RC, Hodgman JE, Kokosky MJ, Teberg AJ 1974 Effect of phototherapy in preterm infants on growth in the neonatal period. J Pediatr 85:563-566

5. Ebbesen F, Edelstein D, Hertel J 1980 Gut transit time and lactose malabsorption during phototherapy I. A study using lactose-free human mature milk. Acta Paediatr Scand 69:65-68

6. Ebbesen F, Edelstein D, Hertel J 1980 Gut transit time and lactose malabsorption during phototherapy II. A study using raw milk from the mothers of the infants. Acta Paediatr Scand 69:69-71

7. Dinari G, Cohen MI, McNamara H, Daum F 1980 The effect of phototherapy on intestinal mucosal enzyme activity in the Gunn rat. Biol Neonate 38:179184

8. Whitington PF 1981 Effect of jaundice phototherapy on intestinal mucosal bilirubin concentration and lactase activity in the congenitally jaundiced Gunn rat. Pediatr Res 15:345-348

9. Whitington PF 1978 Small bowel secretion induced by unconjugated bilirubin. Pediatr Res 12:443

10. Whitington PF, Olsen WA, Odell GB 1981 The effect of bilirubin on the function of hamster small intestine. Pediatr Res 15:1009-1014

11. Li BUK, Whitington PF, Odell GB 1984 The reverse of bilirubin-induced intestinal secretion by agar. Pediatr Res 18:78-82.

12. Anderson S, Grossman MJ 1965 Profile of $\mathrm{pH}$, pressure and potential difference at gastroduodenal junction in man. Gastroenterology 49:364-371

13. Boucher RC, Knowles MR, Stutts MJ, Gatzy JT 1983 Epithelial dysfunction in cystic fibrosis lung disease. Lung 161:1-17

14. Nicolaides N, Koenig A, Ballke EH, Griefahn B, Jaehrig K 1985 The influence of acetylsalicylic acid on the transepithelial potential difference of gastric mucosa. Klin Wochenschr 63:184-187

15. Michaelsson M 1961 Bilirubin determination in serum and urine. Scand J Clin Lab Invest 13(suppl 56):40-50

16. Meisel P, Jaehrig D, Jaehrig K, Meisel M 1981 Generation and characterization of a peroxidase-sensitive photopigment from bilirubin bound to albumin Photobiochem Photobiophys 3:83-85

17. McNeish AS, Mayne A, Ducker DA, Hughes CA 1983 Development of Dglucose absorption in the perinatal period. $J$ Pediatr Gastroenterol Nutr 2(suppl 1):222-226

18. Onishi S, Ogino T, Yokoyama T, Isobe $\mathrm{K}$, Itoh S, Yamakawa T, Hashimoto $\mathrm{T} 1984$ Biliary and urinary excretion rates and serum concentration changes of four photoproducts in Gunn rats during total darkness and low or high illumination. Biochem J 221:717-721

19. DeCurtis M, Saitta F, Matteoli M, Paludetto R, Ciccimarra F, Guandalini S 1982 Evidence for secretory type diarrhea in infants treated by phototherapy. Lancet 1:909

20. Zetterstrom R, Ernster L 1956 Bilirubin, an uncoupler of oxidative phosphorylation in isolated mitochondria. Nature 178:1335-1336

21. Berant M, Diamond E, Brik R. Yurman S 1983 Phototherapy-associated diarrhea. Acta Paediatr Scand 72:853-855 